\title{
Reduction of Trihalomethanes Forming Potential by Adsorption of Natural Organic Matter on Ionic Exchange Resins
}

\author{
Milka M. Vidović ${ }^{1 *}$, Boban Milovanović ${ }^{2}$, Ivana S. Trajković ${ }^{1}$ \\ Jelena G. Momić ${ }^{1}$, Ilija Tomić ${ }^{1}$ \\ ${ }^{1}$ University of Belgrade, Institute of Chemistry, Technology and Metallurgy, Department for Ecology and \\ Technoeconomics, Njegoševa 12, Belgrade, Serbia \\ ${ }^{2}$ Pharma Group D.O.O., Hadži Prodanova, Belgrade, Serbia \\ E-mail:mivibgd@yahoo.com \\ Received November 14, 2009; revised December 16, 2009; accepted December 30, 2009
}

\begin{abstract}
In a sanitation process of drinking water, carbon from the organic matter reacts with chlorine, forming by-products, among which are trihalomethanes (THM). These substances are carriers of mutagenic and cancerogenic potential and hence should be removed in drinking water treatment. Since the natural organic matters are precursors of THM formation, their removal from the water decreases the concentration of THMs. The THM forming potential is the most reliable indicator in evaluation of organic matter removal during drinking water treatment processes. The results have shown that the reaction producing THMs follows second order kinetics. The second order rate constant ranged from $0.024 \mathrm{M}^{-1} \mathrm{~s}^{-1}$ to $0.065 \mathrm{M}^{-1} \mathrm{~s}^{-1}$ at $22{ }^{\circ} \mathrm{C}$ and $\mathrm{pH}$ $=8.2$ for 96 hours. The removal of $78.4 \%$ of natural organic matter, by adsorption on anionic exchange resins, resulted in the THM forming potential reduction by $63.1 \%$. Various fractions of natural organic matter differ in their reactivity with chlorine, which is important when it comes to selection of the adsorption medium in the drinking water treatment processes.
\end{abstract}

Keywords: Natural Organic Matter, Trihalomethanes, Disinfection by Chlorine, Ground Water

\section{Introduction}

Natural organic matter compounds are undesired in drinking water because they react with chlorine during the treatment and distribution processes of drinking water [1-3]. Depending on the conditions (temperature, $\mathrm{pH}$ value, reaction time, the initial concentrations of reaction components $-\mathrm{Cl}_{2}$, organic carbon) and structure of the organic matter in the water, the concentration of chlorinated derivates, including the THMs, may amount to an unacceptably high level [4-7]. The major precursors responsible for the THM forming are considered to be humic and fulvic acids [8-10]. The reaction between THM precursors and chlorine in the chlorination process is not instantaneous; it may last for days, until either the chlorine or the precursor is exhausted. Hence, the amount of THM in drinking water is greater at the consumption site than at the treatment site [7,11-13].

In water chlorination, the electrophile attack on or- ganic matter proceeds via the $\mathrm{Cl}_{2}, \mathrm{H}_{2} \mathrm{OCI}^{+}, \mathrm{Cl}_{2} \mathrm{O}$ or $\mathrm{HOCI}^{-}$and depends on the conditions of the reaction $[6,14]$. These are most commonly the reactions of oxidation, substitution (forming N-chlorinated and C-chlorinated derivates) and addition [10,14-16].

In oxidation reactions the organic matter (such as humic substance) reacts with chlorine, breaking down the anular structure. In the initial stage the pseudohynol form is obtained, followed by the electrophile substitution on the $\mathrm{C}$ atom in $\alpha$-position in relation to the carboxyl group $[10,17]$. Thus formed carbonium ion in the subsequent reaction with chlorine forms trichloromethyl ketone, which is further broken down, producing chloroform [10].

Of importance are also substitution reactions with humic substance. The aromatic carbohydrates, such as phenol and aromatic acids are known to be easily chlorinated in the water medium by $\mathrm{HOCI}^{-}$and $\mathrm{OCI}^{-}$, forming chlorinated analogues. Metoxyl, phenol, and keto groups are 
more reactive with chlorine, than alkyl or carboxyl groups $[17,18]$.

The above mentioned, as well as actual standards, demand elevated criteria in drinking water quality. Such a criteria is the THM forming potential (THMFP). It defines the quantity of THM that can be released in the chlorination process of given water. In the same time it allows for a fairly aqurate comparison of water qualities, with respect to the reactivity of the organic matter present and the effectivity of previous treatment $[12,19]$. The search for new as well as optimization of the existing technological processes for the drinking water treatment, particularly in the field of removal of both organic matter and the products of their reactions with chlorine is outgoing [20,21].

Due to their adsorption properties alkaline macroporous resins may play an important role in removal of THM precursors and thus, in reduction of THM potential of water [22,23]. The use of alkaline macroporous resins is basically connected to the removal of organic matter by adsorption. The humic substance fractions are not equally reactive to chlorine. Therefore, it is important to find out which of them reacting with chlorine and producing THM in water are removed by adsorption. This should be of importance in selecting the adsorbant (resin) in the chosen drinking water treatment.

\section{Materials and Method}

The research was conducted primarily for the purpose of reducing the THM potential in ground waters from the $160-220 \mathrm{~m}$ deep reservoirs in the geotectonic unit of North Banat (North-West Serbia) basin, which is part of the Pannonian basin [24,25]. The ground waters in this area are characterised by an increased concentration of natural organic matter which causes problems in water disinfection processes with chlorine.

Sample 1 of the raw water, discribed above, was collected before entering into a drinking water treatment pilot plant. The sample was analysed for $\mathrm{pH}$, natural organic matter concentration (expressed by the consumption of potassium-permanganate) [26], humic substance concentration [27], UV extinction at $254 \mathrm{~nm} \mathrm{[27],} \mathrm{TOC} \mathrm{-}$ total organic carbon concentration and THM concentration [27]. The concentration of the total organic carbon (TOC) was measured by the "lab TOC, model 2100" [28]. The sample was packed into a tinted glass bottle (with the appropriate teflon septum and a screw cap) were a microsyringe dipped down to the bottle bottom, a quantity of $34 \mathrm{mg} / \mathrm{L}$ activated chlorine was added. The quantities of residual chlorine and the THM concentrations were measured 30 minutes after adding activated chlorine and these values were taken as the initial THM forming potential values $\left(\mathrm{THMFP}_{\mathrm{i}}\right)$. After that, the sample was kept at constant temperature of $22^{\circ} \mathrm{C}$ and con- stant $\mathrm{pH}=8.2$ for 96 hours and THM and residual chlorine concentration were measured [27,29-31] in regular intervals. The difference between the amounts of added and the residual chlorine at the moment of analysis is defined as the quantity of chlorine consumed during the reaction period.

The water samples 2, 3 and 4 were taken after the natural organic matter removal column (supplied with anion resin MP 62, manufactured by Lanxess, Germany). Sample 2 was taken 4 hours, sample 310 hours and sample 416 hours after the beginning of work cycle. These samples underwent the same procedure as sample 1 , except that $17 \mathrm{mg} / \mathrm{L}$ of activated chlorine were added to them. Smaller quantities of chlorine were added because of the smaller concentrations of organics.

The extraction of THM and its concentration were performed in the automatic, microprocessor guided, "Purge \& Trap"concentrator manufactured by Tekmar, Model LSC 2000. The THM separation and their concentration estimates were done on the chromatograph with capillary column, Varian, model GC 3400, with electron absorption detector (63 Ni-ECD). The capillary column used was CP-Sil $13 \mathrm{CB}$ for halocarbonhydrates, custom-designed, WCOT fused silica type, $25 \mathrm{~m}$ x $0.32 \mathrm{~mm}$ I.D., film thickness of $1.2 \mu \mathrm{m}$, Chrompack (conditioning was conducted at $180^{\circ} \mathrm{C}$ over the 4 hour period) $[27,31]$. The summ of THM is presented in $\mu \mathrm{g} / \mathrm{dm}^{3} \mathrm{CHCl}_{3}$, the following corrective factors being used in the calculations:

$$
\begin{aligned}
& \quad \text { TTHM }\left(\mu \mathrm{gCHCl}_{3} / \mathrm{dm}^{3}\right) \\
& \quad=\mu \mathrm{gCHCl}{ }_{3} / \mathrm{dm}^{3}+0.728 \mu \mathrm{gCHCl}_{2} \mathrm{Br} / \mathrm{dm}^{3} \\
& \quad+0.574 \mu \mathrm{gCHClBr}_{2} / \mathrm{dm}^{3}+0.472 \mu \mathrm{gCHBr}_{3} / \mathrm{dm}^{3} \\
& \text { or } 1 \mu \mathrm{gCHCl}_{3} / \mathrm{dm}^{3}=119.5 \mu \mathrm{M} \mathrm{CHCl}_{3}
\end{aligned}
$$

The THM forming potential (THMFP) is defined as the difference between the THM concentration measured 30 minutes after chlorination $\left(\mathrm{TTHM}_{\mathrm{i}}\right)$ and the THM concentration measured later at regular intervals $\left(\mathrm{TTHM}_{\mathrm{f}}\right)$ :

$$
\mathrm{THMFP}=\mathrm{TTHM}_{\mathrm{f}}-\mathrm{TTHM}_{\mathrm{i}}
$$

\section{Results and Discussion}

The results of the experiments show that the raw water used was characterized by $\mathrm{pH}$ values from 8.1 to 8.3 ; relatively high concentration of natural organic matter (expressed by the consumption of potassiumpermanganate) from 27 to $30 \mathrm{mg} / \mathrm{L}$; humic substances concentration from 17 to $19 \mathrm{mg} / \mathrm{L}$, total organic carbon (TOC) from 6 to $7 \mathrm{mg} / \mathrm{L}$; UV extinction at $254 \mathrm{~nm}$ from 29 to $33 \mathrm{~m}^{-1}$; and pronounced yellow colour as a consequence of its chemical composition.

\subsection{Chlorination of Raw Water}

The values of the THM quantity as a function of the time 
elapsed for the reaction of organics with activated chlorine are presented in Figure 1. Substantial difference in the THM concentration measured at the beginning, THMFP $_{\mathrm{i}}$ (after 30 minutes) and at the end, $\mathrm{THMFP}_{\mathrm{f}}$ (after 96 hours) of the chlorination is the THM forming potential, $\mathrm{THMFP}_{\mathrm{T}}$. The shape of the curve indicates that the reaction between the THM precursors and chlorine is slow and not instantaneous. It is obvious that the average value of THM quantity as a function of the time of chlorination represents a logaritmic dependence.

Figure 2 presents the THM quantity as a function of the chlorine consumed and shows that the reaction of 1 mole of $\mathrm{Cl}_{2}$ in raw water yields $0.011 \mathrm{M} \mathrm{CHCl}_{3}$.

The THM forming reaction can be presented as:

$$
\mathrm{Cl}_{2}+\mathrm{THMFP} \stackrel{\mathrm{k}}{\longrightarrow} \mathrm{THM}
$$

then the THM forming reaction dependence on time can be written as:

$$
\mathrm{d}[\mathrm{THM}] / \mathrm{d} t=k\left[\mathrm{Cl}_{2}\right][\mathrm{THMFP}]
$$

where: [THMFP] is the concentration of slowly reacting speacies of THM precoursers, $\left[\mathrm{Cl}_{2}\right]$ is the concentration of chlorine at the time $t$ and $k$ is the second order rate constant of THM formation. After integration:

$$
\frac{1}{\left[\mathrm{Cl}_{2}\right]_{\mathrm{i}}-[\mathrm{THMFP}]_{\Gamma}} \ln \left(\frac{\left([\mathrm{THMFP}]_{\Gamma}\left[\mathrm{Cl}_{2}\right]\right)}{\left[\mathrm{Cl}_{2}\right]_{\mathrm{i}}\left([\mathrm{THMFP}]_{\Gamma}-[\mathrm{THM}]\right)}\right)=k t
$$

where: $\left[\mathrm{Cl}_{2}\right]_{\mathrm{i}}$ is the initial concentration of chlorine; $[\mathrm{THMFP}]_{\mathrm{T}}$ is the total concentration of slowly reacting THM precursors $\left([\mathrm{THMFP}]_{\mathrm{T}}=[\mathrm{THMFP}]_{\mathrm{f}}-[\mathrm{THMFP}]_{\mathrm{i}}\right)$; and THM is concentration difference of THM at the time $t$ and THM at the initial time (30 minutes).

Graphically represented Equation (3), using the data from Figure 1 and Figure 2, shows a linear relationship with $t$, having the slope $k$ which is the reaction rate constant $\left(0.025 \mathrm{M}^{-1} \mathrm{~s}^{-1}\right)$. For the sake of simplicity:

$$
Q=\frac{1}{\left[\mathrm{Cl}_{2}\right]_{\mathrm{i}}-\left[\mathrm{THMFP}_{\mathrm{T}}\right.} \ln \left(\frac{\left([\mathrm{THMFP}]_{\mathrm{T}}\left[\mathrm{Cl}_{2}\right]\right)}{\left[\mathrm{Cl}_{2}\right]_{\mathrm{i}}\left([\mathrm{THMFP}]_{\mathrm{T}^{-}}[\mathrm{THM}]\right)}\right)
$$

\subsection{Chlorination of Water after the Natural Organic Matter Removal Column}

The natural organic matter concentration in samples 2, 3, and 4 were reduced to various levels, by adsorption on macroporous resin. The concentration of THM forming was tracked in all the samples in defined time periods and the chlorine consumption was measured. Figure 4 shows the comparison between the logarithmic dependance of the THM quantity in relation to the reaction

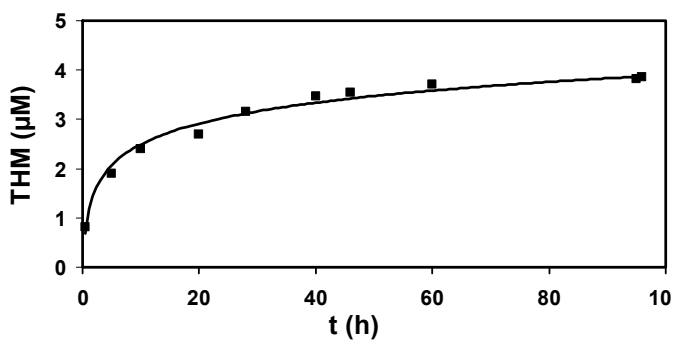

Figure 1. Dependence of the average THM quantity on the time of chlorination process.

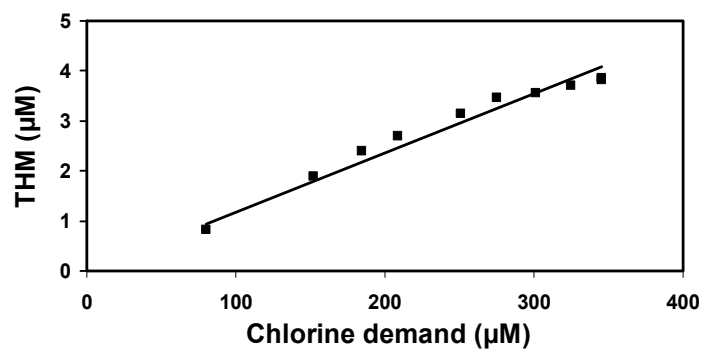

Figure 2. THM quantity dependence on the chlorine consumed in raw water.

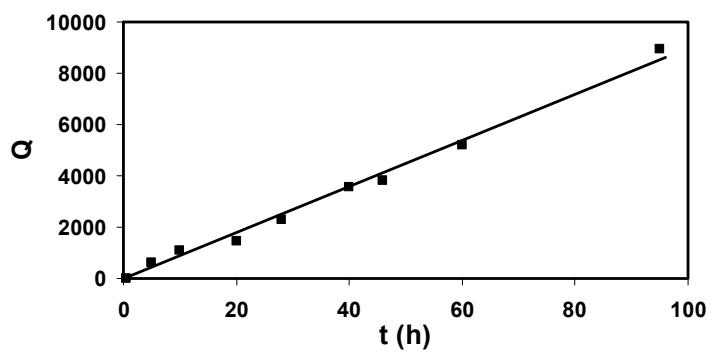

Figure 3. Formation of THM from chlorination of natural organic matter as a function of time in raw water using data from Figure 1 and Figure 2.

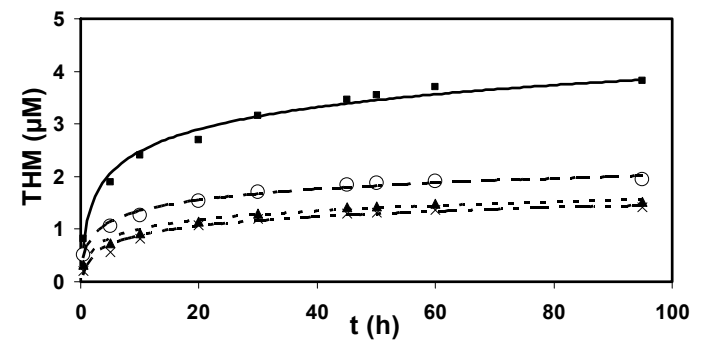

Figure 4. Dependence of the average THM quantity on the time of chlorination process in samples $1(\square), 2(\circ), 3(\Delta)$ and $4(\times)$.

period, for each of the samples 1, 2, 3 and 4 .

These relationships indicate that the smaller the initial concentration of natural organic matter the smaller is the THM potential. In the sample 2 the reaction including 1 mole of $\mathrm{Cl}_{2}$ yields $0.0167 \mathrm{M} \mathrm{CHCl}_{3}$, in the sample 3 yields $0.0128 \mathrm{M} \mathrm{CHCl}_{3}$ and in sample 4 yields $0.0132 \mathrm{M}$ 


\section{$\mathrm{CHCl}_{3}$ (Figure 5).}

By applying the Equation (3) on the data presented in Figure 4, one obtains dependences given in Figure 6 (where $Q$ is presented in Equation (4)). It would appear that the chlorination rate in samples $1,2,3$ and 4 varies, in the raw water (sample 1) being almost two and a half time smaller than in the waters after the natural organic matter removal column (samples 2, 3 and 4). There is also a very small difference in rate constants of the reactions including natural organic matter in samples 2, 3 and 4. It seems that the removal of natural organic matter is faster in water samples 2,3 and $4\left(k \approx 0.025 \mathrm{M}^{-1} \mathrm{~s}^{-1}\right)$ then in raw water $\left(k \approx 0.065 \mathrm{M}^{-1} \mathrm{~s}^{-1}\right)$.

The waters after the natural organic matter removal column have shown distinctive reduction in THM concentration. Thus, THM concentration in sample 2 was reduced by $63.2 \%$, in sample 3 by $60.6 \%$ and in sample 4 by $49.5 \%$.

From the above said one might conclude that natural organic matter removal column is selective, primarily removing the fractions of natural organic matter which slowly react with activated chlorine. This suggests that it is important to make a right choice of adsorbing substance for natural organic matter removal column, favoring the adsorption medium with pronounced affinity towards adsorbing the fractions of natural organic matter which react with chlorine slower.

Some authors [32] used adsorption of natural organic matter as a method for its removal and obtained results which are similar to ours (they removed $81 \%$ of natural organic matter). Other authors have used coagulation [33] or combination of adsorption and coagulation [34] for removal of natural organic matter and achieved poor (25-28\% THMFP removed) or exceptionally good $(\approx$ 93\% THMFP removed) results, respectively. However, our results obtained under different conditions and without coagulation were $30 \%$ less successful in removing THMFP.

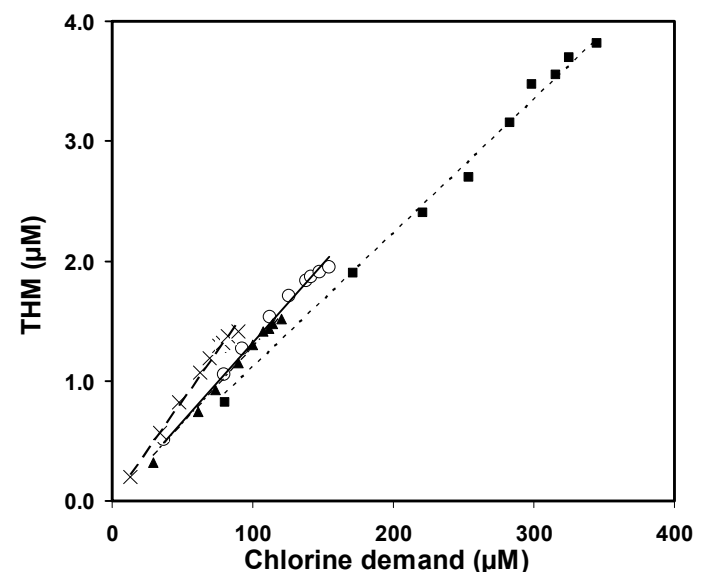

Figure 5. THM quantity dependence on the chlorine consumed in samples $1(\square), 2(\circ), 3(\Delta)$ and $4(\times)$.

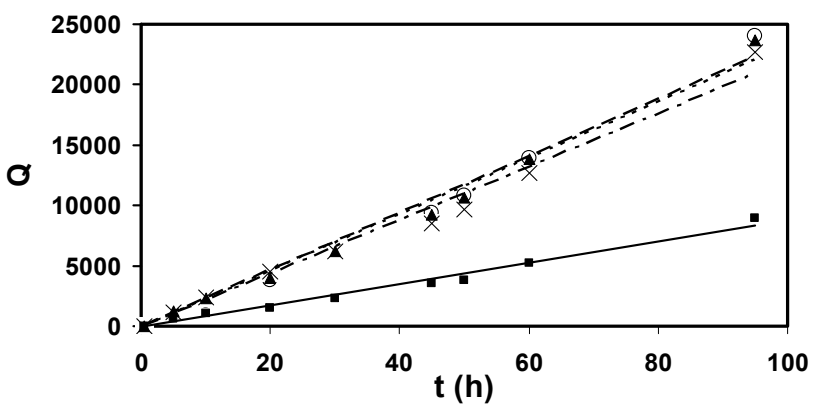

Figure 6. Formation of THM from chlorination of natural organic matter as a function of time in samples $1(\square), 2(\circ), 3$ $(\Delta)$ and $4(\times)$.

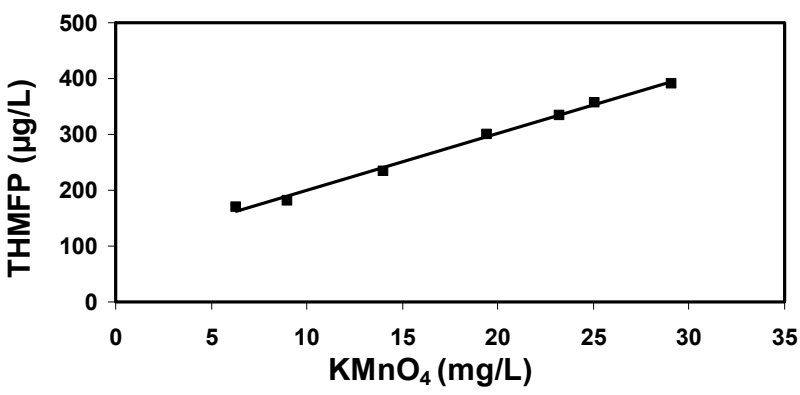

Figure 7. Correlation between the THM forming potential (THMFP) and natural organic matter concentrations $\left(\mathrm{KMnO}_{4}\right)$.

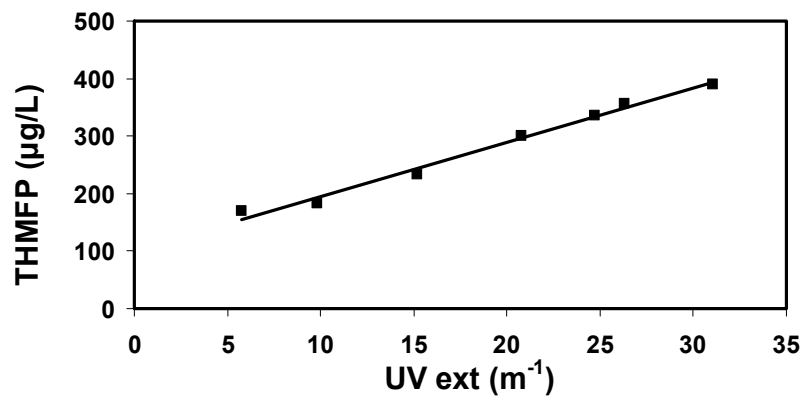

Figure 8. Correlation between the THM forming potential (THMFP) and UV extinction.

There is an additional issue concerning the most adequate method of tracking the concentration of natural organic matter (being the precursors to THM formation) in water. The correlations between the THM potential and natural organic matter concentration (expressed by the consumption of potassium-permanganate, Figure 7); and UV extinction (Figure 8); and total organic carbon (Figure 9); and humic matter concentration (Figure 10); have shown that the most reliable data can be obtained from the correlation between THM forming potential and natural organic matter concentration. It seems slightly more accurate than the correlation between THM forming potential and total organic carbon. 


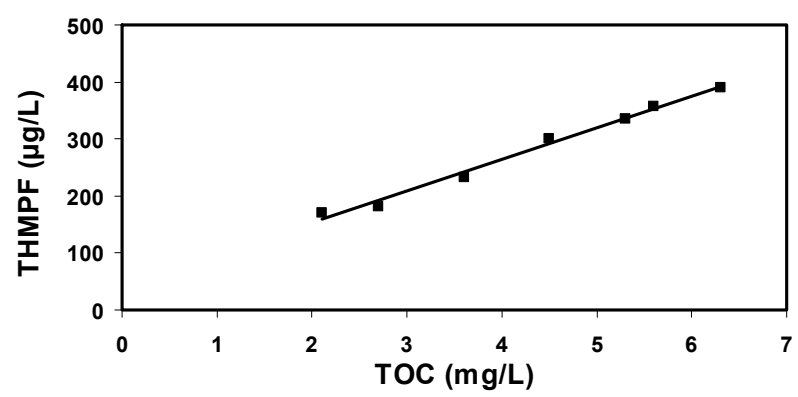

Figure 9. Correlation between the THM forming potential (THMFP) and total organic carbon concentrations (TOC).

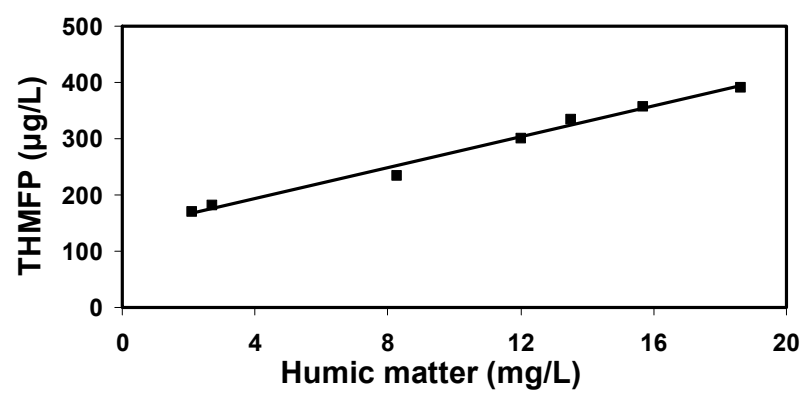

Figure 10. Correlation between the THM forming potential (THMFP) and humic matter concentrations.

\section{Conclusions}

The results have shown that the ground waters of the captured wells in the North Banat region (the Pannonian Plains) contain a relatively high concentration of natural organic matter $\left(6.3 \mathrm{mg} / \mathrm{dm}^{3}\right.$ of total organic carbon on average) which is a result of high humic substances concentration. Different fractions of organic substance are not equally reactive with chlorine, which should be of importance in the selection of adsorption medium for the drinking water treatment processes. The rate of THM formation is found to be smaller for natural organic matter adsorbed on resin in the natural organic matter removal column. The fractions of natural organic matter that were not adsorbed on resin, present a problem, because of their higher rate of reaction with chlorine, i.e., because of the higher second order rate constant in the reactions of THM formation.

\section{Acknowledgement}

The authors would like to acknowledge the funding of the Ministry of Science and Environmental Protection of the Serbian Government (project number: 146021B).

\section{References}

[1] J. V. Hanna, W. D. Johnson, R. A. Quezada, M. A. Wil- son and L. Xlao-Qlao, "Characterization of aqueous humic substances before and after chlorination," Environmental Science \& Technology, Vol. 25, pp. 1160-1164, June 1991.

[2] H. Gallard and U. vonGunten, "Chlorination of natural organic matter: kinetics of chlorination and of THM formation," Water Research, Vol. 36, pp. 65-74, January 2002.

[3] G. Becher, M. N. Ovrum and F. R. Christman, "Novel chlorination by-products of aquatic humic substances," Science of the Total Environment, Vol. 117-118, pp. 509-520, May 1992.

[4] L. Zhi-Sheng, Y. Jun, L. Li and Y. Yu-juan, "Characterization of NOM and THM formation potential in reservoir source water," Desalination and Water Treatment, Vol. 6, pp. 1-4, June 2009.

[5] H. A. Abu Qdais, N. Al-Abed, Z. Al-Ghazawi and F. Abdulla, "Prediction of trihalomethane formation in water distribution systems," Desalination and Water Treatment, Vol. 2, pp. 162-169, February 2009.

[6] S. Sorlini and C. Collivignarelli, "Trihalomethane formation during chemical oxidation with chlorine, chlorine dioxide and ozone of ten Italian natural waters," Desalination, Vol. 176, pp. 103-111, June 2005.

[7] A. D. Nikolaou, T. D. Lekkas and S. K. Golfinopoulos, "Kinetics of the formation and decomposition of chlorination by-products in surface waters," Chemical Engineering Journal, Vol. 100, pp. 139-148, July 2004.

[8] R. F. Christman, D. L. Norwood, D. S. Millington and J. D. Johnson, "Identity and yields of major halogenated products of aquatic fulvic acid chlorination," Environmental Science \& Technology, Vol. 17, pp. 625-628, October 1983.

[9] M. Y. Z. Aboul Eish and M. J. M. Wells, "Assessing the trihalomethane formation potential of aquatic fulvic and humic acids fractionated using thin-layer chromatography," Journal of Chromatography, Vol. 1116, pp. 272 276, May 2006.

[10] J. J. Rook, "Chlorination reactions of fulvic acids in natural waters," Environmental Science \& Technology, Vol. 11, pp. 478-482, May 1977.

[11] A. Jadas-Hecart, A. El Morer, M. Stittou, P. Bouillot and B. Legube, "Modelisation de la demande en chlore d'une eau traitée," Water Research, Vol. 26, pp. 1073-1084, August 1992.

[12] C. J. Peters, R. J. Young and R. Perry, "Factor influencing the formation of haloforms in the chlorination of humic materials," Environmental Science \& Technology, Vol. 14, pp. 1391-1395, November 1980.

[13] E. Koukouraki and E. Diamadopoulos, "Modelling the formation of THM (trihalomethanes) during chlorination of treated municipal wastewater," Water Science and Technology: Water Supply, Vol. 3, pp. 277-284, 2003.

[14] J. J. Rook, "Formation of haloforms during chlorination of natural waters," Journal Water Treat. Exam., Vol. 23, pp. 234-243, 1974.

[15] D. A. Reckhow, P. C. Singer and R. L. Malcolm, "Chlori- 
nation of humic materials: Byproduct formation and chemical interpretations," Environmental Science \& Technology, Vol. 24, pp. 1655-1664, November 1990.

[16] J. C. Morris, "Kinetics of reactions between aqueous chlorine and nitrogenous compounds," In Principles and Applications of Water Chemistry, (eds.) S. D. Faost and J. V. Hunter, John Wiley and Sons, Inc., New York, pp. 22-63, 1967.

[17] G. Guo and X. Chen, "Halogenating reaction activity of aromatic organic compounds during disinfection of drinking water," Journal of Hazardous Materials, Vol. 163, pp. 1207-1212, April 2009.

[18] G. F. Lee and J. C. Morris, "Kinetics of chlorination of phenol-chlorophenolic tastes and odors," International Journal of Air and Water Pollution, Pergamon Press, Vol. 6, pp. 419-431, September - October 1962.

[19] S. K. Golfinopoulos and A. D. Nikolaou, "Survey of disinfection by-products in drinking water in Athens, Greece," Desalination, Vol. 176, pp. 13-24, June 2005.

[20] M. M. Vidović, "Contents and potential of trihalomethane formation in waters reach with humic matters," Specialization Thesis, University of Belgrade, Faculty of Pharmacy, Belgrade, 1998.

[21] M. Vidović, Z. Čukić, N. Đukić, Z. Tamaš and B. Dalmacija, "The removal of aquatic humic substances by macroreticular resins," In Proceedings Third International Symposium and Exhibition on Environmental, Contamination in Central and Eastern Europe, Warsaw, 1996.

[22] M. M. Vidović, "Organic matter removal by adsorption on macroporous resins in drinking water preparation," Master Thesis, University of Novi Sad, Faculty of Natural Sciences and Mathematics, 1996.

[23] J. Naumczyk, L. Szpyrkowicz and F. Zilio Grandi, "Organics isolation from fresh and drinking waters by macroporous anion exchange resins," Water Research, Vol. 23, pp. 1593-1597, December 1989.

[24] M. Vidović, Z. Nikic and B. Milovanović, "Water quality of the north banat basal aquifer system," Geogra - phica Pannonica, Vol. 10, pp. 44-47, October 2006.
[25] Z. Nikić and M. Vidović, "Hydrogeological conditions and quality of ground waters in northern Banat," Pannonian basin, Environmental Geology, Vol. 52, pp. 1075 1084, June 2007.

[26] EN ISO 8467:1995 E, "Water quality - Determination of permanganate index," European Standard.

[27] APHA, AWWA, WPCF, "Standard methods for examination of water \& wastewater (18th edition)," American Public Health Association, Washington, DC, 1989.

[28] BS EN 1484:1997, "Water analysis - guidelines for the determination of total organic carbon (TOC) and dissolved organic carbon (DOC)," European Committee for Standardization, CEN, 1997.

[29] T. Bellar, J. J. Lichtenberg and R. C. Kroner, "The occurrence of organohalides in chlorinated drinking water," Journal of the American Water Works Association (AWWA), Vol. 66, pp. 703-706, November 1974.

[30] R. Brodzinsky and R. L. Vedder, "Trace analysis of volatile halocarbons in water using the HP 19395A headspace sampler gas chromatography," Hewlett - Packard Application, pp. 228-266, 1988.

[31] USEPA, 600/4-88/039, "Methods for the determination of organic compounds in drinking water," Cincinnati, Ohio, pp. 5-29, 1988.

[32] P. H.-S. Kim and J. M. Symons, "Using anion exchange resins to remove THM precursors," Journal of the American Water Works Association (AWWA), Vol. 83, pp. 61-68, December 1991.

[33] C. Musikavong, S. Wattanachira, T. F. Marhaba and P. Pavasant, "Reduction of organic matter and trihalome thane formation potential in reclaimed water from treated industrial estate wastewater by coagulation," Journal of Hazardous Materials, Vol 127, pp. 48-57, December 2005.

[34] D. A. Fearing, J. Banks, S. Guyetand, C. M. Eroles, B. Jefferson, D. Wilson, P. Hillis, A. T. Campbell and S. A. Parsons, "Combination of ferric and MIEXs for the treatment of a humic rich water," Water Research, Vol 38, pp. 2551-2558, May 2004. 